\title{
ACADEMICS AT THREE AFRICAN UNIVERSITIES ON THE PERCEIVED UTILISATION OF THEIR RESEARCH
}

\author{
N. Boshoff* \\ e-mail: scb@sun.ac.za

\section{H. Esterhuyse*} \\ e-mail: hesterhuyse@sun.ac.za

\section{N. Wachira-Mbui*} \\ e-mail: dmbui@uonbi.ac.ke \\ E. T. Owoaje* \\ e-mail: eowoaje@com.ui.edu.ng
}

\section{T. Nyandwi*}

e-mail: nyandwi.theogene@yahoo.fr

\section{S. Mutarindwa*}

e-mail: Samuel.Mutarindwa@ju.se

${ }^{*}$ Centre for Research on Evaluation, Science and Technology (CREST) and DST-NRF Centre of Excellence in Scientometrics and Science, Technology and Innovation Policy (SciSTIP)

Stellenbosch University

Stellenbosch, South Africa

\section{ABSTRACT}

This article contributes to emerging knowledge on the utilisation of university research in subSaharan Africa. A survey was conducted comprising 463 academics at three African universities: the University of Ibadan (Nigeria), the University of Nairobi (Kenya) and the University of Rwanda. The study investigated the agreement between two measures of research utilisation and highlighted the types of research interactions associated with instances of perceived research utilisation, whilst taking into account the different categories of intended beneficiaries. The first measure, a single question, required the respondents to indicate to what extent the stated intended beneficiaries had utilised the research as planned. The second measure operationalised a stage model of research utilisation. Responses at the "upper end" of both measures were labelled "true" research utilisation. A percentage reduction in utilisation was observed when cross-tabulating the two measures - from 48 per cent who believed that research utilisation occurred to some extent (upper end of first measure), to 35 per cent who held the same opinion and who obtained above- 
average scores on the stage model of utilisation (upper end of second measure). For the subgroup at the upper end of both measures, the larger share of cases (54\%) exemplified the instrumental utilisation of research. This subgroup was found to be involved in traditional academic research practices and participated in a number of outreach activities targeting non-academic audiences.

Keywords: Africa, impact, interactions, research, use, utilisation, university

\section{INTRODUCTION}

Concerns about the utilisation of research-based knowledge, which extends beyond academic utilisation, rose to prominence in the 1970s, when discussions about the relevance of social research for state-funded public policies and programmes started to dominate international policy debates. The initial discussions mainly involved exchanges between social scientists and policymakers, which found expression in the academic literature in the form of studies on the link between knowledge and policy (Larsen 1980; Weiss 1978; 1979; 1980). Since then, knowledge utilisation has become an umbrella term for almost any study dealing with the application of research-based knowledge outside the academic environment. Research utilisation is considered a subset of knowledge utilisation, where research is knowledge that is generated through systematic inquiry and the scientific method (Boshoff 2014a). From a constructivist perspective, research is seen as "an organized search process in which knowledge is designed" (Kok and Schuit 2012, 3).

This article contributes to emerging knowledge on the utilisation of university research in sub-Saharan Africa. A survey was conducted of the principal investigators of research projects at three African universities, focussing on whether and how the participating academics believed that their research had been used. The surveyed universities were the University of Ibadan in Nigeria, the University of Nairobi in Kenya and the University of Rwanda. The study followed in the footsteps of a previous survey of research utilisation conducted in South Africa (Boshoff and Mouton 2005) and other investigations in Canada (Amara, Ouimet and Landry 2004; Landry, Amara and Lamari 2001a; 2001b) and Australia (Cherney et al. 2013; Cherney and McGee 2011). Three questions guided the current study:

- Who are the intended beneficiaries of research projects at the three study universities?

- Did the intended beneficiaries utilise the project research as planned, based on the perception of the academics and by using different measures of research utilisation?

- Which kinds of direct, indirect and financial interactions are associated with instances of perceived research utilisation? 
Before discussing the survey methodology and presenting findings in relation to the questions listed, a brief overview of relevant literature is provided, focussing on the conceptualisation of research utilisation. The latter is understood either as different types or as a series of cumulative stages. The literature overview also includes a discussion of so-called "productive interactions" (direct, indirect or financial interactions) that recently started to feature in discussions of the social impact of research (Molas-Gallart and Tang 2011; Spaapen and Van Drooge 2011), and which can be considered mechanisms to achieve research utilisation.

\section{TYPES OF RESEARCH UTILISATION}

Weiss (1979) discusses seven models that explain how research-based knowledge moves into practice. Four of the models (problem-solving model, tactical model, political model and enlightenment model) are relevant to the current discussion as they highlight the different types of research utilisation. The remaining three models will not be discussed here as they reflect on other aspects of research utilisation: the linear order of utilisation in cases where the findings of basic research are defined and tested through applied research and then developed into technologies for application (knowledge-driven model), the disorderly set of interactions that characterises the search for relevant information by research users (interactive model), and the sometimes inter-connectedness between social science research and policy as two intellectual pursuits of society (intellectual enterprise of society model).

The four relevant models, in turn, represent three types of research utilisation: instrumental, symbolic and conceptual. Although these models focus on research use in a policy context, they also apply to other domains of practice (Boshoff 2014b; Estabrooks 1999).

The policy-driven model describes cases where politicians (or any potential user of research) seek out existing research or commission new research in the hope of finding a solution to a problem. Since the research results are of direct interest to politicians, such results often find direct application in decision-making and policy measures (Weiss 1979). Such acting on research results in specific, direct ways is known as the instrumental use of research (Beyer and Trice 1982). In other practice domains (e.g. nursing), instrumental utilisation is characterised by a concrete application of research results (i.e. the results inform specific decisions or interventions), and the results are often also "translated into a material and useable form, such as a protocol" (Estabrooks 1999, 204). For Boshoff (2014b), for example in winemaking, instrumental use represents instances of winemakers doing things differently in the winery because of specific research results.

Both the tactical and political models (Weiss 1979) exemplify the symbolic use of research. In the tactical model, the research result itself is of no interest to politicians. What 
interests them is the idea of research - the fact that research was conducted or considered in relation to a specific issue, which the politicians hope will provide proof of their responsiveness. The political model, on the other hand, refers to cases where politicians use research results to justify their pre-established views. Their actions and decisions are not really affected by the research results because the information is used as ammunition to support a particular view. Beyond the policy sphere, e.g. in winemaking practice, symbolic use could refer to instances where specific research results are used to support a winemaker's personal belief concerning winemaking (Boshoff 2014b). The symbolic use of research is closely related to persuasive utilisation, where research results are used to persuade others to adopt a pre-determined position (Strandberg et al. 2014).

According to the enlightenment model of research utilisation, politicians find it difficult to identify any research that has shaped their decisions. Still, because they engage with research they realise that, together with other information, research-based knowledge often provides them with an underlying set of ideas on which to base their decisions and actions (Weiss 1979). Characteristic of the enlightenment model is the so-called "knowledge creep", or a "diffused, undirected seepage of social research into the policy sphere" (Weiss 1978, 23). This points to the conceptual use of research utilisation - research gradually changes the thinking but not necessarily the actions of a knowledge user, as research is used to enlighten (Estabrooks 1999). For instance, research can give rise to a number of concepts and theories that pervade the policymaking process (Weiss 1979). A more practice-based example of conceptual utilisation is that of winemakers gradually developing a better understanding of some aspect of their winemaking because of research (Boshoff 2014b).

\section{STAGES OF RESEARCH UTILISATION}

In addition to viewing research utilisation as involving different types, research utilisation can also be seen as a process and not as a single, discreet event (Beyer and Trice 1982).

Knott and Wildavsky (1980) specify seven standards of utilisation where each standard corresponds to a different stage in the research utilisation process. The stages are hierarchical because any stage incorporates all preceding stages. The first stage (reception standard) is found where the research findings have reached the potential user. The second stage of utilisation occurs when the potential user has read and understood the research findings (cognition standard). The remaining five stages comprise the following:

- the research findings have changed the frame of reference of the potential user, e.g. a change in preference, attitude or understanding (reference standard); 
- $\quad$ the potential user has made an effort to adopt the research findings (effort standard);

- the research findings have been adopted formally through reference in a policy or practice protocol (adoption standard);

- the policy or practice protocol has been implemented formally (implementation standard); and

- broader benefits have been produced as a result of the implementation (impact standard).

Landry et al. (2001a, 397) slightly modified some of the above seven standards to produce a so-called "ladder" of research utilisation. Their conception comprises six stages: transmission, cognition, reference, effort, influence and application. Table 1 provides the descriptions. Each stage builds upon the previous, which means that research utilisation is portrayed as a cumulative process that comprises a number of stages closely related to the actions of the knowledge users. The six stages also constitute a useful empirical measure of research utilisation. This was applied in previous studies (e.g. Cherney et al. 2013; Cherney and McGee 2011) and also in the current study.

Table 1: The six-stage ladder of research utilisation

\begin{tabular}{|l|l|}
\hline \multicolumn{1}{|c|}{ Stages } & \multicolumn{1}{c|}{ Descriptions } \\
\hline Stage 1: Transmission & I transmitted my research results to the practitioners and professionals concerned. \\
\hline Stage 2: Cognition & $\begin{array}{l}\text { My research reports were read and understood by the practitioners and professionals } \\
\text { concerned. }\end{array}$ \\
\hline Stage 3: Reference & $\begin{array}{l}\text { My work has been cited in the reports, studies and strategies of action elaborated by } \\
\text { practitioners and professionals. }\end{array}$ \\
\hline Stage 4: Effort & $\begin{array}{l}\text { Efforts were made by practitioners and professionals to adopt the results of my } \\
\text { research. }\end{array}$ \\
\hline Stage 5: Influence & $\begin{array}{l}\text { My research results influenced the choice and decision of practitioners and } \\
\text { professionals. }\end{array}$ \\
\hline Stage 6: Application & $\begin{array}{l}\text { My research results gave rise to applications and extension by the practitioners and } \\
\text { professionals concerned. }\end{array}$ \\
\hline
\end{tabular}

Source: Landry et al. (2001b, 336)

\section{PRODUCTIVE INTERACTIONS OF RESEARCH}

To date, the focus of impact assessment has largely been on the quantitatively measured final outcomes of programmes. With the introduction of "societal impact of research" into the picture, the focus of impact assessment in research shifted from final outcomes to the research process and the associated use of research by individuals and groups closely linked to the research process (Upton, Vallance and Goddard 2014). This shift was necessitated by the long time frames to impact in research, and especially the difficulty of showing attribution of research. The new interaction approaches to research impact therefore move in time and space away from final outcomes (impact) to research use. Such research use is achieved through researchers' interactions with society (including during the undertaking of research) (Robinson- 
Garcia, Van Leeuwen and Rafols 2017; Spaapen and Van Drooge 2011).

One interaction approach to research impact focusses on so-called "productive interactions", or "encounters between researchers and stakeholders in which academically sound and socially valuable knowledge is developed and used" (De Jong et al. 2014, 92). An interaction is considered productive "when it leads to efforts by stakeholders to somehow use or apply research results" (Spaapen and Van Drooge 2011, 212). Research impact, according to this approach, can be concluded when a productive interaction results in "stakeholders doing new things or doing things differently" (Molas-Gallart and Tang, 2011, 219). Research use is therefore an important criterion in deciding whether an interaction is productive and whether impact occurred.

Productive interactions mainly fall within three types: direct, indirect and financial. An indirect productive interaction occurs when research use takes place as a result of an interaction between researchers and stakeholders through the means of a medium. A medium can be anything from an article to a podcast, and in the current study, included peer-reviewed articles and contract reports. A direct productive interaction occurs without the presence of an intermediary medium. An example of this would be informal meetings with potential stakeholders of a research project or direct supervision of $\mathrm{PhD}$ students. The last type, financial interactions, are found where the use results from funding or contributions in kind. Examples of this include funding from international donors or the private sector (Spaapen and Van Drooge 2011; Van den Akker and Spaapen 2017).

The current study highlighted the interactions that are associated with instances of perceived research utilisation and which, for that reason, could be considered productive.

\section{METHODOLOGY}

The study was conducted as three separate but related surveys that were administered in 2014 and 2015. In the case of UI and UoN, all faculties at those universities were surveyed. Only two of the six colleges at UR were included: the College of Medicine and Health Sciences (CMHS) and the College of Science and Technology (CST).

\section{Survey questionnaire}

The questionnaire by Boshoff and Mouton (2005) on research utilisation was modified for this study. The introductory section collected background information, which included the name of the college or faculty of the academics. The names of the colleges/faculties were used to classify the respondents into one of four mutually exclusive research fields: agricultural and veterinary sciences, health sciences, natural sciences and engineering, and social sciences and humanities. 
The main section of the questionnaire required information about a single research project, which the respondents had to select based on three criteria. Firstly, the respondents had to have been the principal investigator of the project, or the project had to have formed part of the research for the respondents' master's or doctoral degree. Secondly, the project had to have been completed during the preceding ten years or, if it was ongoing, must have produced some results already. Thirdly, the majority of the research work had to have been completed while the respondent was affiliated with the university under study.

For the project selected, the respondents had to specify the research collaborators and the source of project funding. In the case of both, a list of country-specific options was provided (which were afterwards reclassified into shared categories) (see Table 6). The respondents also indicated the intended beneficiaries they had in mind when conceptualising the research. A list of seven beneficiaries was provided, which ranged from peers in own discipline to society at large. More than one selection could be made.

The main section also included two measures of research utilisation. The first asked the respondents to indicate to what extent they believed that the intended beneficiaries had utilised the research as planned. One of four responses was possible: "yes, to some extent", "yes, to little extent", "no, not at all" and "don't know". In the case of the "yes" responses, the respondents had to give concrete examples of how the research was utilised (an open-ended question). The second measure was the six-stage ladder of research utilisation (Landry et al. 2001a; 2001b). Here they had to rate six statements that represented the different stages of the utilisation process (from transmission to application) (see again Table 1). The response options were: "strongly agree", “agree”, “disagree”, “strongly disagree” and “don’t know”.

Finally, the respondents were asked how they had communicated the findings of their research project. A list of 25 modes of communication was provided, which reflected publications, presentations, workshops, training and supervision, informal meetings and organisational structures. Multiple selections were possible.

\section{Survey administration}

At UI and UR, the email addresses of academic staff were obtained from the relevant institutional offices. At UoN, only one email address was used - that of a university list server, to which all academic staff members subscribed. A cover letter was sent to the academics via these emails, to introduce the survey and to request their participation. The letter included a hyperlink to access the questionnaire and to complete it online (in SurveyMonkey®). However, this strategy did not produce the expected result, since the first survey response was very poor. A possible explanation was that academics at these universities mostly communicated via a 
personal email address (e.g. Gmail or Yahoo) and did not always rely on the official university email system.

A dual follow-up strategy was therefore implemented. In the case of UoN, personalised emails were sent to the research-active staff at the institution to motivate participation, and copies of questionnaires were also printed and dropped off at the offices of academic staff. At UI, as a follow-up strategy to maximise the survey response, paper copies were placed in the departmental mailboxes of academic staff. At UR, face-to-face visits were arranged.

Responses from the paper copies were captured manually onto the online survey system. University-specific datasets were downloaded from the system and merged into a single data file in the Statistical Package for Social Sciences (SPSS, version 23). After data cleaning, the survey response was 13 per cent for UI (206 of 1536 academic staff), 8 per cent for UoN (134 of 1584 academic staff), and 22 per cent for UR (123 of 556 academic staff at the two colleges). The final dataset comprised 463 responses.

\section{RESULTS}

This section presents the findings of the survey in terms of the three research questions that guided the analysis.

\section{Who are the intended beneficiaries of research projects at the three study universities?}

In the top part of Table 2, the four broad research fields are cross-tabulated with the intended beneficiaries the respondents had in mind when conceptualising the research. The list of beneficiaries is not mutually exclusive. In the bottom part of the table, the seven beneficiaries are classified into three mutually exclusive categories (only academic, only non-academic and both) and cross-tabulated with the same broad fields. The last column on the right indicates statistically significant differences $(p<0.05)$ between the four fields in terms of the research beneficiaries. Significance was determined by means of a z-test for the equality of proportions.

The broad and generic category of general public/society/community occupies the second place $(43 \%)$, after peers in own discipline. Almost a third of respondents $(32 \%)$ identified specific interest groups (e.g. farmers or teachers) as beneficiaries. Government was more frequently mentioned as an intended beneficiary compared to industry (34\% versus $18 \%)$ but significant differences were only found for industry. Specifically, research in the agricultural and veterinary sciences (38\%) was more likely to be conducted with industry beneficiaries in mind, compared to both the health sciences $(6 \%)$ and the social sciences and humanities $(15 \%)$. Only 5 per cent of researchers identified contracting agencies as intended beneficiaries. No significant field differences were observed for this category of beneficiary. 
Table 2: Intended beneficiaries of research, by broad research field

\begin{tabular}{|c|c|c|c|c|c|c|}
\hline \multirow[b]{2}{*}{ Intended beneficiaries } & \multirow[b]{2}{*}{$\begin{array}{l}\text { All fields } \\
(\mathrm{N}=424)\end{array}$} & \multicolumn{4}{|c|}{ Broad research fields } & \multirow[b]{2}{*}{$\begin{array}{l}\text { Significant } \\
\text { differences } \\
\text { between the } \\
\text { four fields } \\
(p<0.05)\end{array}$} \\
\hline & & $\begin{array}{c}{[\mathrm{A}]} \\
\text { Agricultural } \\
\text { and } \\
\text { veterinary } \\
\text { sciences } \\
(\mathrm{N}=65) \\
\end{array}$ & $\begin{array}{c}{[B]} \\
\text { Health } \\
\text { sciences } \\
(\mathrm{N}=171)\end{array}$ & $\begin{array}{c}{[\mathrm{C}]} \\
\text { Natural } \\
\text { sciences } \\
\text { and } \\
\text { engineering } \\
(\mathrm{N}=142) \\
\end{array}$ & $\begin{array}{c}\text { [D] } \\
\text { Social } \\
\text { sciences } \\
\text { and } \\
\text { humanities } \\
(\mathrm{N}=46)\end{array}$ & \\
\hline \multicolumn{7}{|c|}{ Seven overlapping categories } \\
\hline $\begin{array}{l}\text { Colleagues/scholars/ } \\
\text { peers in own discipline }\end{array}$ & $63 \%$ & $60 \%$ & $67 \%$ & $56 \%$ & $70 \%$ & None \\
\hline $\begin{array}{l}\text { General public/society/ } \\
\text { community }\end{array}$ & $43 \%$ & $37 \%$ & $45 \%$ & $46 \%$ & $39 \%$ & None \\
\hline $\begin{array}{l}\text { Ministry/government } \\
\text { agency }\end{array}$ & $34 \%$ & $29 \%$ & $35 \%$ & $33 \%$ & $39 \%$ & None \\
\hline Specific interest groups & $32 \%$ & $42 \%$ & $32 \%$ & $24 \%$ & $41 \%$ & None \\
\hline $\begin{array}{l}\text { Colleagues/scholars/peer } \\
\mathrm{s} \text { in other disciplines }\end{array}$ & $28 \%$ & $17 \%$ & $34 \%$ & $23 \%$ & $41 \%$ & $A \& D$ \\
\hline Industry/business/firm(s) & $18 \%$ & $38 \%$ & $6 \%$ & $24 \%$ & $15 \%$ & $\begin{array}{l}\text { A\&B, A\&D, } \\
\text { B\&C }\end{array}$ \\
\hline The contracting agency & $5 \%$ & $0 \%$ & $5 \%$ & $6 \%$ & $11 \%$ & None \\
\hline \multicolumn{7}{|c|}{ Three mutually exclusive categories } \\
\hline $\begin{array}{l}\text { Both academic and non- } \\
\text { academic audiences }\end{array}$ & $50 \%$ & $57 \%$ & $50 \%$ & $44 \%$ & $54 \%$ & None \\
\hline $\begin{array}{l}\text { Only non-academic } \\
\text { audiences }\end{array}$ & $32 \%$ & $34 \%$ & $29 \%$ & $38 \%$ & $26 \%$ & None \\
\hline $\begin{array}{l}\text { Only academic } \\
\text { audiences }\end{array}$ & $18 \%$ & $9 \%$ & $21 \%$ & $18 \%$ & $20 \%$ & $A \& B$ \\
\hline
\end{tabular}

In the bottom part of Table 2, the two categories of peers (in own or other disciplines) are classified as academic audiences and all other beneficiaries as non-academic audiences; hence, three mutually exclusive groupings. When controlling for the overlap between beneficiaries, only 18 per cent of respondents had an exclusive focus on peers (academics). Respondents in the agricultural and veterinary sciences, compared to those in the health sciences, were less likely to focus on academic audiences in their research (9\% versus $18 \%)$. Finally, half of respondents $(50 \%)$ had both academic and non-academic audiences in mind when conceptualising their research.

\section{Did the intended beneficiaries utilise the project research as planned, based on different measures of perceived research utilisation?}

Here the focus shifts to the two self-reported measures of research utilisation and their overlap. The first measure shows the extent to which the respondents believed that the intended project beneficiaries had used the research as planned (Figure 1). As can be seen, the respondents were very optimistic in their response - 48 per cent believed that there has been utilisation to some extent. Only 8 per cent stated that there was no utilisation at all. 


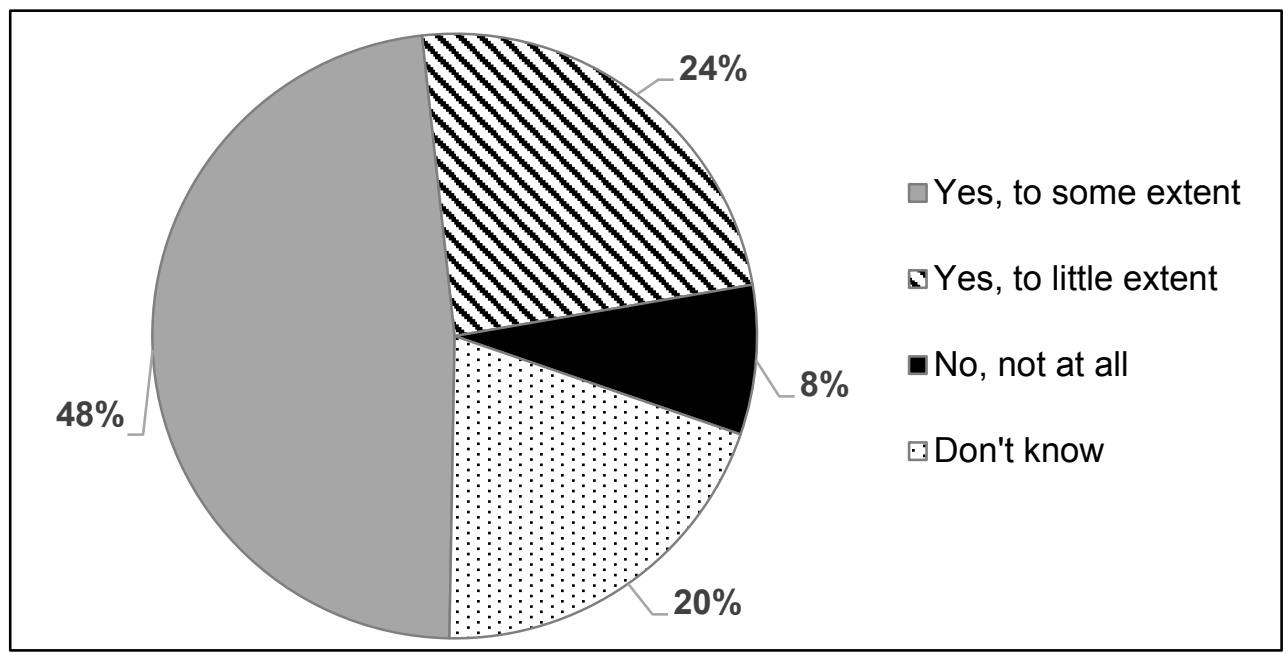

Figure 1: Extent to which the principal investigators believed that the intended beneficiaries used the research as planned $(\mathrm{N}=424)$

The responses for the second measure, the six-stage ladder of research utilisation (Landry et al. 2001a; 2001b), are summarised in Table 3. It shows to what extent the respondents agreed with the six statements that represent the different stages of research utilisation. Research utilisation is portrayed here as a hierarchical process where each stage (at least in theory) incorporates all previous stages in the ladder of utilisation.

Table 3: Extent to which the principal investigators agreed with six statements corresponding to the different stages of research utilisation

\begin{tabular}{|l|c|c|c|c|c|}
\hline \multicolumn{1}{|c|}{ Stages } & $\begin{array}{c}\text { Strongly } \\
\text { agree }\end{array}$ & Agree & Disagree & $\begin{array}{c}\text { Strongly } \\
\text { disagree }\end{array}$ & Don't know \\
\hline 1. Transmission $(\mathrm{N}=423)$ & $33 \%$ & $51 \%$ & $8 \%$ & $3 \%$ & $5 \%$ \\
\hline 2. Cognition $(\mathrm{N}=411)$ & $21 \%$ & $48 \%$ & $9 \%$ & $3 \%$ & $19 \%$ \\
\hline 3. Reference $(\mathrm{N}=411)$ & $18 \%$ & $35 \%$ & $12 \%$ & $4 \%$ & $30 \%$ \\
\hline 4. Adoption $(\mathrm{N}=401)$ & $15 \%$ & $43 \%$ & $12 \%$ & $5 \%$ & $25 \%$ \\
\hline 5. Influence $(\mathrm{N}=403)$ & $18 \%$ & $36 \%$ & $12 \%$ & $4 \%$ & $30 \%$ \\
\hline 6. Application $(\mathrm{N}=406)$ & $17 \%$ & $37 \%$ & $14 \%$ & $2 \%$ & $30 \%$ \\
\hline
\end{tabular}

Note: See Table 1 for the wording of the statements representing each stage.

Table 3 provides only partial support for a hierarchical or cumulative model of research utilisation. As the respondents "climb" the ladder of stages, some decreases are observed in the shares of "strongly agree" and "agree" responses. However, the decreases are not always as consistent as would be expected. Particularly with the onset of stage four, adoption, the pattern of systematic decreases (in the shares of "strongly agree" and "agree" responses) becomes disrupted.

Overall, the percentages of respondents who either disagreed or strongly disagreed are never higher than 20 per cent whilst the percentages of those who either agreed or strongly 
agreed are always above 50 per cent for any stage. The increasing levels of "don't know" responses (from $5 \%$ in stage one to $30 \%$ in stage six) are probably related to the fact that it becomes harder for researchers to determine what has happened to their research the further it is removed from them in time and space.

Figure 2 presents the results on the stage perspective of research utilisation differently. It shows the percentages of respondents who passed certain combinations of stages. A "pass" means either a "strongly agree" or "agree" response. As can be seen, 29 per cent of respondents indicated that their research passed all six stages, i.e. the research moved from transmission to application without skipping any of the stages between. However, the largest share of respondents (37\%) belong to a category labelled "inconsistent". These are respondents who passed anything from one to five stages but at the same time skipped one or more preceding stages, or one or more of the stages between those selected. Essentially "inconsistent" means any response pattern other than the ones mentioned in Figure 2. The relatively large share of inconsistencies provides additional grounds for questioning the stage model of research utilisation.

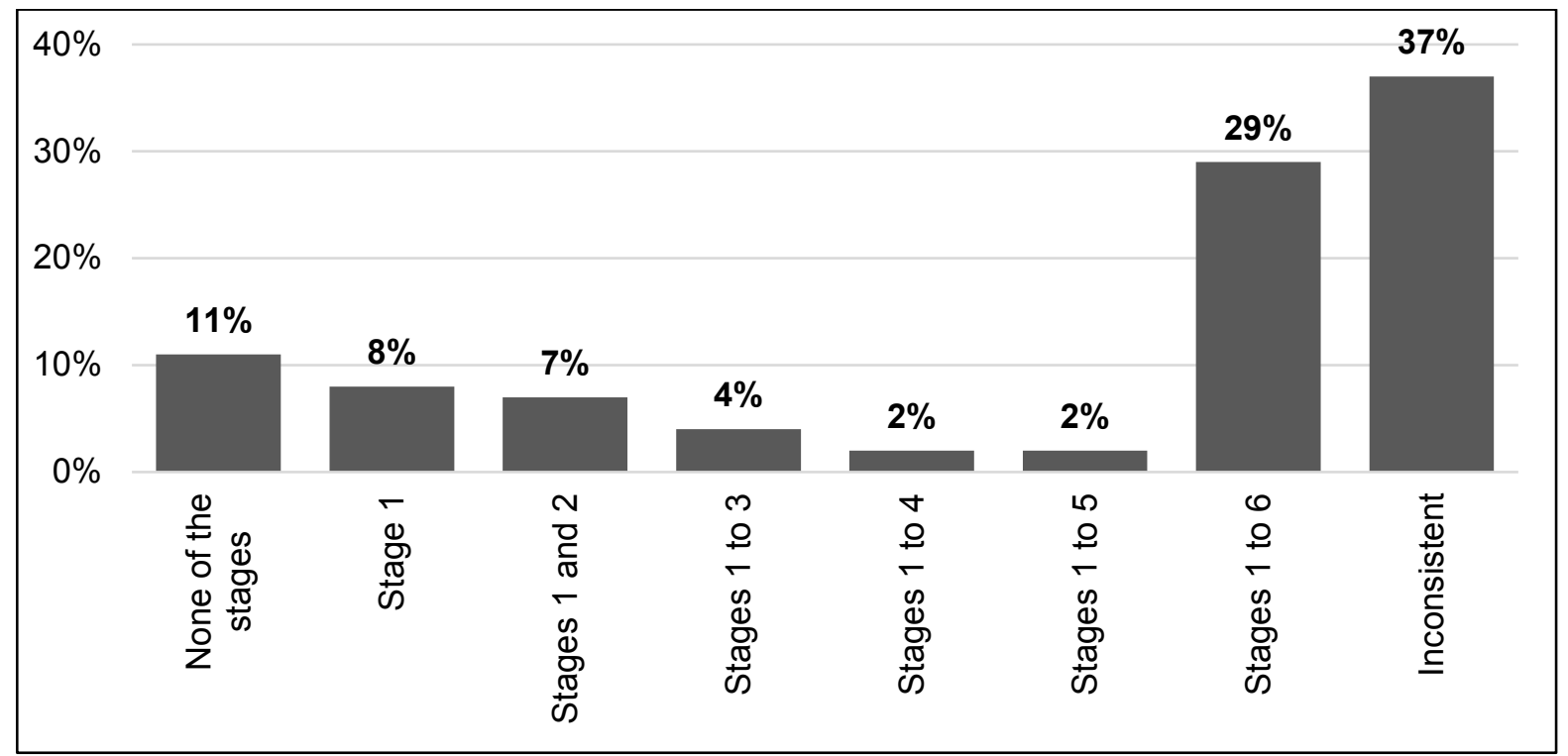

Figure 2: Percentage of principal investigators who passed the different stages of research utilisation $(\mathrm{N}=430)$

Next, for the second measure, a composite score was calculated for each respondent. The composite score took into account the assumption of stage hierarchy by assigning a larger weight to higher-order stages and a smaller weight to lower-order stages. This means that a weight of 1 was assigned to stage one, a weight of 2 to stage two and, finally, a weight of 6 to stage six. The response options of the individual items were also assigned weights: strongly agree (4), agree (3), disagree (2), strongly disagree (1), and don't know (0). Each respondent received a weighted score for any item, which was calculated as the product of the two sets of 
weights. For instance, a respondent who disagreed with the stage one item received a weighted score of 2 (i.e. $2 \times 1$ ) for that item. On the other hand, a respondent who disagreed with the stage four item received a weighted score of 8 (i.e. $2 \times 4$ ) for that item. Similarly, a respondent who strongly agreed with the stage 6 item received a weighted score of 24 (i.e. $4 \times 6$ ) for that item. The composite measure was created by summing the weighted scores for all items. In theory, the scores on the composite measure could range from 0 to 84 . A score of 84 would reflect someone who strongly agreed with all six items (calculated as $4+8+12+16+20+24$ ). The composite measure was dichotomised by using the median (50th percentile) of the distribution as cut-off. The median was 46 (with a mean of 43 and a standard deviation of $25 ; \mathrm{N}=430$ ).

In order to establish whether some respondents merely found it important to state that utilisation occurred without that really being the case, the two self-reported measures of research utilisation were cross-tabulated. Table 4 shows the cross-tabulation (using the dichotomised second measure) for each of the three broad categories of beneficiary. Chi-square tests were performed to determine the statistical significance of the relationship between the two measures.

Table 4: Relationship between the two measures of research utilisation, by intended beneficiaries

\begin{tabular}{|c|c|c|c|c|}
\hline \multirow{2}{*}{$\begin{array}{c}\text { Intended } \\
\text { beneficiaries }\end{array}$} & \multirow[b]{2}{*}{ Measure 1} & \multicolumn{2}{|c|}{ Measure 2} & \multirow{2}{*}{$\begin{array}{c}\text { Statistical } \\
\text { significance }\end{array}$} \\
\hline & & $\begin{array}{c}\text { Score: } 0-45 \\
\text { (below average) }\end{array}$ & $\begin{array}{c}\text { Score: } 46-84 \\
\text { (above average) }\end{array}$ & \\
\hline \multirow{5}{*}{$\begin{array}{l}\text { Only academic } \\
\text { audiences }\end{array}$} & Yes, to some extent & $17(24 \%)$ & $24(34 \%)$ & \multirow{5}{*}{$\begin{array}{c}x^{2}=11.936 \\
d f=3 \\
p<0.05\end{array}$} \\
\hline & Yes, to little extent & $7(10 \%)$ & $4(6 \%)$ & \\
\hline & No, not at all & $4(6 \%)$ & $1(1 \%)$ & \\
\hline & Don't know & $12(17 \%)$ & $1(1 \%)$ & \\
\hline & Total & 40 & 30 & \\
\hline \multirow{5}{*}{$\begin{array}{l}\text { Only non- } \\
\text { academic } \\
\text { audiences }\end{array}$} & Yes, to some extent & $15(12 \%)$ & $42(32 \%)$ & \multirow{5}{*}{$\begin{array}{c}x^{2}=32.122 \\
d f=3 \\
p<0.05\end{array}$} \\
\hline & Yes, to little extent & $18(14 \%)$ & $14(11 \%)$ & \\
\hline & No, not at all & $10(7 \%)$ & $3(2 \%)$ & \\
\hline & Don't know & $25(19 \%)$ & $4(3 \%)$ & \\
\hline & Total & 68 & 63 & \\
\hline \multirow{5}{*}{$\begin{array}{l}\text { Both academic } \\
\text { and non-academic } \\
\text { audiences }\end{array}$} & Yes, to some extent & $19(9 \%)$ & $77(38 \%)$ & \multirow{5}{*}{$\begin{array}{c}x^{2}=54.747 \\
d f=3 \\
p<0.05\end{array}$} \\
\hline & Yes, to little extent & $26(13 \%)$ & $33(16 \%)$ & \\
\hline & No, not at all & $10(5 \%)$ & $3(2 \%)$ & \\
\hline & Don't know & $31(15 \%)$ & $5(3 \%)$ & \\
\hline & Total & 86 & 118 & \\
\hline
\end{tabular}

Note: The eight percentages for each category of intended beneficiaries add up to $100 \%$.

All three cross-tabulations in Table 4 are statistically significant $(\mathrm{p}<0.05)$, which means that the two measures of research utilisation do correlate. The shaded cells indicate, for each category of beneficiary, what could be regarded as a "true" instance of utilisation. For instance, 131 respondents indicated that only non-academics were the intended beneficiaries of their 
projects. However, for only 42 (or $32 \%$ ) of the 131 respondents, one could conclude that research utilisation most probably occurred. These are the ones who replied "yes, to some extent" to the question representing the first measure, and who simultaneously obtained an above-average score on the second measure. Such "true" instances of research utilisation range between 32-38 per cent across the three beneficiary categories, with an average of 35 per cent overall. Thus, by considering the interaction between the two measures, an accurate proxy for research utilisation could be established. In Table 4, these are the three values in the shaded cells.

These "true" instances of research utilisation were subsequently cross-tabulated with the responses to the open-ended question that asked for concrete examples of research utilisation. The text responses were coded in terms of the three utilisation types: instrumental, conceptual and symbolic. A fourth category of scientific utilisation was also introduced. Below are two examples for each coding category to illustrate the classification in Table 5:

\section{- Instrumental:}

"The poor farmers who suffer from iron deficiency in their diets have started planting and consuming bio-fortified beans."

"On the basis of the result, the ministry ... organised workshops for teachers and principals of schools in all the four administrative areas of the country."

- Conceptual:

"Awareness on good housing systems and awareness on public health issues."

"Feedback from the socioeconomic aspect of work has benefited organisation X [name deleted] in understanding rice farmers' expectation."

- Symbolic/persuasive:

"The research was able to verify the claim and justify the usage of the plant by the local people."

"A finding on the extent of use of foreign technical workers in [an industry] is being used as part of the rationale for establishing a regional centre of excellence for high-level training in the industry."

- Scientific:

"One of the papers published has been quoted by other works in that field at least 16 times."

"The results of the research created linkages and interest from other researchers in my discipline."

- Unclear/vague:

"Biodiesel produced can be used in cars as fuel."

"Making the environment of farmers more cohesive through sustainable livelihoods." 
Table 5: Utilisation types in the subset of "true" research utilisation, for three beneficiary groups

\begin{tabular}{|l|c|c|c|c|c|}
\hline \multirow{2}{*}{ Types of utilisation } & \multirow{2}{*}{$\begin{array}{c}\text { Total } \\
\mathbf{( N = 1 4 3 )}\end{array}$} & $\begin{array}{c}\text { IA] } \\
\text { Only academic } \\
\text { audiences } \\
\mathbf{( N = 2 4 )}\end{array}$ & $\begin{array}{c}\text { Intended beneficiaries } \\
\text { Only non- } \\
\text { academic } \\
\text { audiences } \\
\mathbf{( N = 4 2 )}\end{array}$ & $\begin{array}{c}\text { Significant } \\
\text { differences } \\
\text { Both } \\
\text { academic and } \\
\text { non-academic } \\
\text { audiences } \\
\mathbf{( N = 7 7 )}\end{array}$ & $\begin{array}{c}\text { between the } \\
\text { three } \\
\text { beneficiary } \\
\text { groups } \\
(\mathbf{p}<\mathbf{0 . 0 5})\end{array}$ \\
\hline Instrumental & $54 \%$ & $29 \%$ & $67 \%$ & $55 \%$ & A\&B, A\&C \\
\hline Scientific & $13 \%$ & $50 \%$ & $7 \%$ & $31 \%$ & A\&B, B\&C \\
\hline Conceptual & $2 \%$ & $4 \%$ & $2 \%$ & $1 \%$ & $\#$ \\
\hline Symbolic/persuasive & $1 \%$ & $0 \%$ & $0 \%$ & $3 \%$ & $\#$ \\
\hline Unclear/vague & $20 \%$ & $21 \%$ & $21 \%$ & $19 \%$ & None \\
\hline No response & $3 \%$ & $0 \%$ & $7 \%$ & $1 \%$ & $\#$ \\
\hline
\end{tabular}

Note: Percentages do not add to 100 per cent in the columns because some answers were classified in more than one utilisation category.

\# The cases were too few for statistical significance testing.

Only 1 per cent and 2 per cent of the respondents (in the subset of "true" utilisation cases) provided examples that could be classified as the conceptual and symbolic utilisation of research (Table 5). Instrumental utilisation was the most prominent form of utilisation (54\% overall). Instances of instrumental utilisation was significantly higher for the two categories of intended beneficiaries that included non-academics $(67 \%$ and $55 \%)$ than for the category without non-academics (29\%). Similarly, scientific utilisation was higher for the two categories that included academics as beneficiaries than for the category without academic beneficiaries (50\% and $31 \%$ versus $7 \%)$.

\section{Which kinds of direct, indirect and financial interactions are associated with instances of perceived research utilisation?}

The analysis emanating from this question was confined to the 143 cases described as "true" instances of research utilisation. In this subset, all interactions between researchers and stakeholders/users were considered productive because they were associated with "efforts by stakeholders to somehow use or apply research results" (Spaapen and Van Drooge 2011, 212). Research collaboration was interpreted as a form of direct interaction, project funding as a form of financial interaction, and the different mechanisms of research communication as a combination of both direct and indirect interaction. Table 6 shows the occurrences of these interactions in the subset of 143 cases, broken down by the category of intended beneficiary.

The shaded cells in Table 6 highlight interactions that were specified by at least one third of the respondents in each of the three beneficiary categories. A number of traditional practices of academic research seem to be prominent across the three groups. Examples include 
collaborating with fellow academics and students (67-73\%), presenting at academic conferences (67-86\%), publishing articles in peer-reviewed journals (60-82\%), and supervising master's and doctoral students (42-65\%). A first observation therefore is that a core of traditional academic research practices - representing both direct and indirect interactions underlies the instances of "true" research utilisation.

Table 6: Productive interactions (research collaboration, project funding and communication mechanisms) in the subset of "true" research utilisation, for three beneficiary groups

\begin{tabular}{|c|c|c|c|c|}
\hline & \multicolumn{3}{|c|}{ Intended beneficiaries } & \multirow[b]{2}{*}{$\begin{array}{c}\text { Significant } \\
\text { differences } \\
\text { between the } \\
\text { three } \\
\text { beneficiary } \\
\text { groups } \\
(p<0.05)\end{array}$} \\
\hline & $\begin{array}{c}{[\mathrm{A}]} \\
\text { Only } \\
\text { academic } \\
\text { audiences } \\
(\mathrm{N}=24)\end{array}$ & $\begin{array}{l}\quad[\mathrm{B}] \\
\text { Only non- } \\
\text { academic } \\
\text { audiences } \\
\quad(\mathrm{N}=42)\end{array}$ & $\begin{array}{c}\text { [C] } \\
\text { Academic } \\
\text { and non- } \\
\text { academic } \\
\text { audiences } \\
(\mathrm{N}=77)\end{array}$ & \\
\hline \multicolumn{5}{|l|}{ Nature of research collaboration } \\
\hline No collaboration & $25 \%$ & $19 \%$ & $26 \%$ & None \\
\hline Collaborated with academics/researchers/students & $67 \%$ & $73 \%$ & $73 \%$ & None \\
\hline Collaborated with ministries/government agencies & $8 \%$ & $29 \%$ & $21 \%$ & None \\
\hline Collaborated with intended user(s) & $4 \%$ & $14 \%$ & $14 \%$ & None \\
\hline Collaborated with industry/business & $4 \%$ & $14 \%$ & $4 \%$ & B\&C \\
\hline $\begin{array}{l}\text { Collaborated with non-governmental organisations } \\
\text { (NGOs) }\end{array}$ & $0 \%$ & $19 \%$ & $7 \%$ & $A \& B, B \& C$ \\
\hline \multicolumn{5}{|l|}{ Source of project funding } \\
\hline Own pocket (self) & $46 \%$ & $19 \%$ & $39 \%$ & $A \& B, B \& C$ \\
\hline International funding agency/donor & $33 \%$ & $45 \%$ & $40 \%$ & None \\
\hline Own university & $8 \%$ & $19 \%$ & $14 \%$ & None \\
\hline Ministries/government agencies & $8 \%$ & $12 \%$ & $12 \%$ & None \\
\hline NGOs & $4 \%$ & $2 \%$ & $10 \%$ & None \\
\hline Business/private sector & $0 \%$ & $7 \%$ & $9 \%$ & None \\
\hline Other & $21 \%$ & $2 \%$ & $7 \%$ & $A \& B, A \& C$ \\
\hline \multicolumn{5}{|l|}{ Research communication mechanisms } \\
\hline $\begin{array}{l}\text { Conference presentations to predominantly academic } \\
\text { audiences }\end{array}$ & $79 \%$ & $67 \%$ & $86 \%$ & $B \& C$ \\
\hline Articles in peer-reviewed journals & $75 \%$ & $60 \%$ & $82 \%$ & $B \& C$ \\
\hline Consultations/assistance to potential users & $54 \%$ & $50 \%$ & $60 \%$ & None \\
\hline Supervision of master's and doctoral students & $42 \%$ & $48 \%$ & $65 \%$ & None \\
\hline Informal meetings with potential users/teams & $46 \%$ & $55 \%$ & $58 \%$ & None \\
\hline Training through coursework & $46 \%$ & $24 \%$ & $57 \%$ & $\mathrm{~B} \& \mathrm{C}$ \\
\hline Presentations to expert committees/panels & $38 \%$ & $55 \%$ & $38 \%$ & None \\
\hline Published conference proceedings & $33 \%$ & $31 \%$ & $60 \%$ & $B \& C$ \\
\hline Training through workshops & $33 \%$ & $40 \%$ & $60 \%$ & $A \& C$ \\
\hline Personnel exchanges/secondments & $21 \%$ & $19 \%$ & $36 \%$ & $\mathrm{~B} \& \mathrm{C}$ \\
\hline Participation in consortia & $25 \%$ & $19 \%$ & $26 \%$ & None \\
\hline Articles in popular journals/magazines & $21 \%$ & $17 \%$ & $17 \%$ & None \\
\hline $\begin{array}{l}\text { Conference presentations to predominantly non- } \\
\text { academic audiences }\end{array}$ & $13 \%$ & $31 \%$ & $40 \%$ & None \\
\hline Technical manuals & $13 \%$ & $19 \%$ & $9 \%$ & None \\
\hline Technology transfer offices & $8 \%$ & $7 \%$ & $8 \%$ & None \\
\hline Science parks & $4 \%$ & $5 \%$ & $4 \%$ & None \\
\hline Contract reports & $8 \%$ & $45 \%$ & $30 \%$ & $A \& B$ \\
\hline Books/monographs & $8 \%$ & $12 \%$ & $17 \%$ & None \\
\hline Chapters in books & $4 \%$ & $10 \%$ & $17 \%$ & None \\
\hline Spin-off companies & $0 \%$ & $2 \%$ & $1 \%$ & None \\
\hline Technology incubators & $0 \%$ & $0 \%$ & $3 \%$ & None \\
\hline Written input to official policy documents & $4 \%$ & $24 \%$ & $23 \%$ & None \\
\hline Presentations at fairs/public exhibitions/road shows & $0 \%$ & $12 \%$ & $10 \%$ & None \\
\hline Patenting & $0 \%$ & $7 \%$ & $4 \%$ & None \\
\hline Licensing & $0 \%$ & $2 \%$ & $0 \%$ & None \\
\hline
\end{tabular}


A second observation is that a number of outreach activities to non-academic audiences also seem to be associated with the 143 instances of "true" research utilisation. These include consultations or assistance to potential users (50-60\%), informal meetings with potential users (46-58\%), presentations to expert committees and panels (38-55\%), and training through workshops (40-60\%). All of these are examples of direct interactions between researchers and user representatives. Indirect interactions between researchers and users (i.e. through written media) seem to be of limited importance in this subset of "true" utilisation cases. Relatively small numbers of respondents, for instance, specified articles in popular magazines (17-21\%), technical manuals (9-19\%) or written input to official policy documents (4-24\%) as a mode of research communication of their project. The exception are contract reports. As an example of indirect interactions, contract reports were mentioned by 45 per cent of the respondents who specified non-academic audiences only.

In terms of financial interactions, international agencies funded between 33 and 50 per cent of the projects associated with "true" research utilisation. To a certain extent, the research that underlies these 143 projects could be seen as serving the interests of international funding agencies. Finally, the absence of financial interactions also seems to play a role in research utilisation at the three universities, particularly where the research audience includes other academics. Between 39 and 46 per cent of the respondents in this category stated that they funded the research out of their own pocket. However, the funding sources in Table 6 are not mutually exclusive, which means that personal funds could have supplemented other sources of funding in some instances.

\section{DISCUSSION}

An empirical study of research utilisation typically uses one or more of three approaches. It can "track forwards" from the research that was conducted to highlight its consequences, or it can "track backwards" from a selected policy or practice decision to highlight the relevant research influences. Alternatively, it can highlight the engagements and interactions that facilitate research utilisation (Davies, Nutley and Walter 2005). The current study used aspects from both the forward tracking and the interaction approaches. Forward tracking, as applied in this study, was incomplete as it did not ask the intended beneficiaries whether they had used the research findings as claimed by the academic researchers. The perspectives of the academics therefore need to be taken at face value. That said, it was never the objective of this study to verify the utilisation perceptions of academics externally. The primary objectives were to investigate the extent of agreement between two measures of research utilisation and to highlight the interactions that are associated with instances of perceived research utilisation, whilst taking 
into account the different categories of intended beneficiaries.

Overall, 63 per cent of the respondents specified as intended beneficiaries the peers in their own discipline. This figure is not unrealistically high when viewed in the light of other studies. For instance, in a study by Boshoff (2017), 73 per cent of the South African authors of articles stated that individuals at their own university had a direct interest in the outcome of their research or were directly affected by its results. Moreover, in the current study, only 5 per cent of academics identified contracting agencies as intended beneficiaries with no significant differences between fields. This might be a reflection on the fact that some of the universities, such as UI, attract low levels of external funding overall (Owoaje and Desmennu 2014). It could also relate to institutional funding practices. Often, a central university office - and not the academic researchers - receives funding from a donor or contracting agency. The central office then makes the external funding available to the academic community through a formal application and proposal reviewing process. In that way, the academic researchers could perceive the funding as "internal" and in the process, lose track of the contracting agency as a possible beneficiary.

Moreover, the two measures of research utilisation were part of a self-administered survey and thus both relied on self-reporting. Such measures are never totally free from socially desirable responding, although the bias is reported to be less for self-administered surveys, particularly web surveys, than for interviewer-administered surveys (Kreuter, Presser and Tourangeau 2008). Of particular interest here, was the agreement between the two measures. An answer that corresponds to the "upper end" of both measures was considered the best proxy for research utilisation and labelled "true" research utilisation. A percentage reduction in perceived utilisation was observed when the two measures were cross-tabulated - from 48 per cent who believed that research utilisation occurred to some extent (upper end of first measure) to 35 per cent who were of the same opinion but, in addition, also obtained above-average scores on the stage measure of utilisation (upper end of second measure). The subgroup at the upper end of both measures was found to be involved in traditional academic research practices whilst participating in a number of outreach activities to non-academic audiences.

The larger share of utilisation examples (54\%) provided by the above subgroup highlighted the instrumental utilisation of research. Only 2 per cent gave examples of the conceptual utilisation of research. This is in contrast with the finding by Cherney and McGee (2011), namely that research is most often used conceptually. However, the study by Cherney and McGee followed a different approach. Their respondents were asked to rate statements that corresponded to the different types of utilisation, not to provide examples of utilisation which were then coded into the different types. Conceptual utilisation reflects cognitive processes 
(strategic thinking, enlightenment, etc.) that occur in the minds of research users. Instances of conceptual and symbolic utilisation would therefore not be visible to academic researchers in the same way that instrumental utilisation would (since the latter refers to specific observable actions).

In addition to an over-reliance on the self-reporting of academics, the study also had other shortcomings. For instance, for analytical reasons, the three universities had to be combined while they actually reflect different institutional and national dynamics. The same lack of differentiation applied to the different fields of research in this study. It needs to be pointed out that studies of research utilisation, although insightful on their own, are part of the practice of research evaluation. Research evaluation is increasingly emphasising the importance of performing "evaluation in context", since it is important to consider "the local context in which academic research groups are embedded, and how ... this influence knowledge dynamics" (De Jong et al. 2011, 62). Hence, institutional and field-specific case studies of the uptake, valorisation, utilisation and impact of academic research are required to do justice to the dynamics of context (Cherney et al. 2013; Ngwenya and Boshoff 2018). Ideally, the case studies should not slavishly apply available analytical tools, such as the productive interaction approach (Spaapen and Van Drooge 2011), but expand these and develop new tools and frameworks for research evaluation that are rooted in the African reality.

\section{ACKNOWLEDGMENT}

This research was funded with support from the Development Research Uptake in Sub-Saharan Africa (DRUSSA) programme. The DRUSSA programme ran from 2011 to 2016 and was funded by the Department for International Development (DFID), which is a United Kingdom government department responsible for administering overseas aid.

\section{NOTE}

Four of the authors participated in the research as part of the requirements for the MPhil programme in Science and Technology Studies at CREST, Stellenbosch University. They are Dr Damaris WachiraMbui (University of Nairobi), Prof Eme Owoaje (University of Ibadan), and Mr Theogene Nyandwi and Mr Samuel Mutarindwa (both University of Rwanda). All four were registered students at Stellenbosch University at the time of the research.

\section{REFERENCES}

Amara, N., M. Ouimet and R. Landry. 2004. New evidence on instrumental, conceptual, and symbolic utilization of university research in government agencies. Science Communication 26(1): 75-106.

Boshoff, N. 2014a. Types of knowledge in science-based practices. JCOM: Journal of Science Communication 13(3): 1-16. https://jcom.sissa.it/sites/default/files/documents/JCOM_1303_ 2014_A06.pdf(Accessed 12 September 2017). 
Boshoff, N. 2014b. Utilisation of scientific research by South African winemakers. JCOM: Journal of Science Communication 13(1): 1-18. https://jcom.sissa.it/sites/default/files/documents/JCOM 1301_2014_A01.pdf (Accessed 12 September 2017).

Boshoff, N. 2017. South African corresponding authors on perceived beneficiaries and the nature of university research. South African Journal of Higher Education 31(3): 46-62.

Boshoff, N. and J. Mouton. 2005. A survey of research utilisation. Stellenbosch: Centre for Research on Science and Technology, Stellenbosch University.

Beyer, J. M. and H. M. Trice. 1982. The utilization process: A conceptual framework and synthesis of empirical findings. Administrative Science Quarterly 27: 591-622.

Cherney, A., B. Head, P. Boreham, J. Povey and M. Ferguson. 2013. Research utilization in the social sciences: A comparison of five academic disciplines in Australia. Science Communication 35(6): 780-809.

Cherney, A. and T. R. McGee. 2011. Utilization of social science research: Results of a pilot study among Australian sociologists and criminologists. Journal of Sociology 47(2): 144-162.

Davies, H., S. Nutley and I. Walter. 2005. Assessing the impact of social science research: Conceptual, methodological and practical issues. Background discussion paper for the ESRC Symposium on Assessing Non-academic Impact of Research, Research Unit for Research Utilisation, University of St Andrews, May. https://www.odi.org/sites/odi.org.uk/files/odi-assets/events-documents/ 4381.pdf (Accessed 20 August 2017).

De Jong, S., K. Barker, D. Cox, T. Sveinsdottir and P. van den Besselaar. 2014. Understanding societal impact through productive interactions: ICT research as a case. Research Evaluation 23(2): 89102.

De Jong, S. P. L., P. van Arensbergen, F. Daemen, B. van der Meulen and P. van den Besselaar. 2011. Evaluation of research in context: An approach and two cases. Research Evaluation 20(1): 61-72.

Estabrooks, C. A. 1999. The conceptual structure of research utilization. Research in Nursing and Health 22(3): 203-216.

Knott, J. and A. Wildavsky. 1980. If dissemination is the solution, what is the problem? Knowledge: Creation, Diffusion, Utilization 1(4): 537-578.

Kok, M. O. and A. J. Schuit. 2012. Contribution mapping: A method for mapping the contribution of research to enhance its impact. Health Research Policy and Systems 10: 1-16.

Kreuter, F., S. Presser and R. Tourangeau. 2008. Social desirability bias in CATI, IVR, and web surveys: The effects of mode and question sensitivity. Public Opinion Quarterly 72(5): 847-865.

Landry, R., N. Amara and M. Lamari. 2001a. Climbing the ladder of research utilization: Evidence from social science research. Science Communication 22(4): 396-422.

Landry, R., N. Amara and M. Lamari. 2001b. Utilization of social science research knowledge in Canada. Research Policy 30(2): 333-349.

Larsen, J. K. 1980. Knowledge utilization. What is it? Knowledge: Creation, Diffusion, Utilization 1(3): 421-442.

Molas-Gallart, J. and P. Tang. 2011. Tracing "productive interactions" to identify social impacts: An example from the social sciences. Research Evaluation 20(3): 219-226.

Ngwenya, S. and N. Boshoff. 2018. Valorisation: The case of the Faculty of Applied Sciences at the National University of Science and Technology, Zimbabwe. South African Journal of Higher Education 32(2): 215-236.

Owoaje, E. T. and O. M. Desmennu. 2014. Research activities and identified constraints among academic staff at the University of Ibadan, Ibadan, Nigeria. Paper presented at the 7th WARIMA International Conference and Workshop, University of Jos, 2-7 March.

Robinson-Garcia, N., T. N. van Leeuwen and I. Rafols. 2017. Using almetrics for contextualised mapping of societal impact: From hits to networks. https://ssrn.com/abstract=2932944 (Accessed 15 May 2017). 
Spaapen, J. and L. van Drooge. 2011. Introducing "productive interactions" in social impact assessment. Research Evaluation 20(3): 211-218.

Strandberg, E., A. C. Eldh, H. Forsman, A. Rudman, P. Gustavsson and L. Wallin. 2014. The concept of research utilization as understood by Swedish nurses: Demarcations of instrumental, conceptual, and persuasive research utilization. Worldviews on Evidence-Based Nursing 11(1): $55-64$.

Upton, S., P. Vallance and J. Goddard. 2014. From outcomes to process: Evidence for a new approach to research impact assessment. Research Evaluation 23(4): 352-365.

Van den Akker, W. and J. Spaapen. 2017. Productive interactions: Societal impact of academic research in the knowledge society. http://www.leru.org/files/general/LERU_Position_Paper_Societal_ Impact.pdf (Accessed 1 August 2017).

Weiss, C. H. 1978. Broadening the concept of research utilization. Sociological Symposium 21: 20-33.

Weiss, C. H. 1979. The many meanings of research utilization. Public Administration Review 39(5): 426-431.

Weiss, C. H. 1980. Knowledge creep and decision accretion. Knowledge: Creation, Diffusion, Utilization 1(3): 381-404. 